\title{
Effect of chronic theophylline treatment on the methacholine dose-response curve in allergic asthmatic subjects
}

\author{
C.P. Page, T. Cotter, S. Kilfeather, P. Sullivan, D. Spina, J.F. Costello
}

Effect of chronic theophylline treatment on the methacholine dose-response curve in allergic asthmatic subjects. C.P. Page, T. Cotter, S. Kilfeather, P. Sullivan, D. Spina, J.F. Costello. CERS Journals Ltd 1998.

ABSTRACT: Theophylline is a bronchodilator and immunomodulator drug which has recently been demonstrated to attenuate the recruitment and activation of inflammatory cells into lungs of asthmatics. This study investigated the effect of chronic treatment with theophylline for its ability to alter airway responsiveness, as indicated by changes in airway sensitivity and reactivity to inhaled methacholine.

The subjects studied were mild asthmatics who relied on $\beta$-agonist medication only and who were randomized into two groups, one receiving theophylline (median dose $250 \mathrm{mg}$ twice daily; range 250-375 mg twice daily) and the other placebo. A number of parameters was measured before and after treatment, including baseline forced expiratory volume in one second (FEV1), the provocative concentration of methacholine causing a $20 \%$ fall in FEV1 (PC20; sensitivity), dose-response slope (reactivity) and percentage eosinophils, eosinophil cationic protein and T-cell markers in peripheral blood (by flow cytometry).

After 2 months of treatment with theophylline there was a significant lowering of airway reactivity (slope) to methacholine and improvement in methacholine sensitivity (PC20). However, such changes were not associated with any significant change in the number or activation status of eosinophils and lymphocytes in peripheral blood.

In conclusion, chronic treatment with theophylline reduces the reactivity of the airways to methacholine, which might be beneficial in the treatment of persistent asthma. The cellular mechanisms of this improvement remain to be clarified. Eur Respir J 1998; 12: 24-29.
The Sackler Institute of Pulmonary Pharmacology, Dept of Respiratory Medicine, King's College School of Medicine and Dentistry, London, UK.

Correspondence: C.P. Page

The Sackler Institute of Pulmonary Pharmacology

Dept of Respiratory Medicine

King's College School of Medicine and Dentistry

Bessemer Road

London SE5 9PJ

UK

Fax: 441713463589

Keywords: Asthma hyperresponsiveness theophylline

Received: September 21997

Accepted after revision March 221998

Supported by BykGulden (Germany).
Theophylline has been used for the treatment of asthma for many years, although the mechanism of action of this drug has yet to be elucidated. Whilst theophylline has long been recognized as a drug capable of relaxing airway smooth muscle, recent clinical and experimental data have suggested that it may also possess anti-inflammatory activity.

The intravenous administration of theophylline or enprophylline prior to allergen [1] or toluene di-isocyanate [2] has been shown to inhibit the development of the late asthmatic response [1] without any significant effect on the acute bronchoconstrictor response or the associated bronchial hyperresponsiveness to methacholine [2-4]. Recent studies have investigated the effect of low-dose theophylline on the inflammatory process in the airway when administered chronically. In a randomized, double-blind, cross-over [5] and parallel group study [4], the effect of theophylline or placebo was investigated on various inflammatory indices following once and twice daily treatment for 1 and 5, weeks respectively. The late asthmatic response to allergen was reduced in subjects treated with theophylline after 5 weeks [4], despite a mean plasma concentration of $7.8 \mu \mathrm{g} \cdot \mathrm{mL}^{-1}$. Analysis of bronchial biopsies taken from mild asthmatics treated with low-dose theophylline (plasma levels, $6.7 \mu \mathrm{g} \cdot \mathrm{mL}^{-1}$ ) over 6 weeks re- vealed a significant reduction in EG2+ cells (activated eosinophils) and total number of eosinophils [6]. Similarly, a reduction in CD3+ T-lymphocytes and expression of various activation markers on CD4+ T-lymphocytes, including human lymphocyte antigen (HLA-DR) and very late antigen (VLA-1), was observed in bronchoalveolar lavage fluid [7]. Furthermore, a reduction in CD4+, CD8+ T-lymphocytes and interleukin (IL)- 4 and IL-5 containing cells was observed in bronchial biopsies from asthmatics who were taking theophylline over a 6 week period [8]. In other studies, withdrawal of theophylline from asthmatics who were taking glucocorticosteroids resulted in a significant deterioration of their disease $[9,10]$ and a concomitant rise in the number of CD4+, and CD8+ T-lymphocytes in bronchial biopsies [10]. This clinical observation is of interest as it occurred in patients who were also taking regular anti-inflammatory glucocorticosteroids, suggesting that the anti-inflammatory action of theophylline may be complimentary to that of glucocorticosteroids.

In many studies, the mean provocative concentration causing a $20 \%$ fall in forced expiratory volume in one second (PC20) to inhaled methacholine or histamine has been shown to correlate well with asthma severity [11] and is thought to be a consequence of airway inflammation [12, 13]. However, asthmatics have both an increased sensitivity 
(conventionally assessed by $\mathrm{PC} 20$ of inhaled histamine or methacholine) and increased reactivity (an increase in slope and loss of plateau response to inhaled spasmogens), which may be caused by different underlying mechanisms [14]. Whilst many studies have been undertaken to evaluate the effect of drugs on airway sensitivity to spasmogens, only a few studies have been undertaken to evaluate the effect of antiasthma drugs on airway reactivity. Thus, chronic treatment with either short- or long-acting $\beta_{2}$-adrenoceptor agonists $[15,16]$ has been demonstrated to increase airway reactivity, whereas the anti-inflammatory glucocorticosteroid budesonide $[17,18]$ decreased airway reactivity to spasmogens. Thus, whilst theophylline has been investigated for its effect on airway sensitivity (PC20) to spasmogens $[2-4,19,20]$, no study to date has evaluated the effect of this drug on the full dose-response curve to inhaled methacholine. In the present study, daily administration of theophylline for 2 months was evaluated with respect to airway hyperresponsiveness in mild asthmatic subjects in a parallel-design placebo-controlled trial.

\section{Methods}

\section{Subjects}

Thirty six mild atopic, nonsmoking, asthmatic subjects (20 males and 16 females) volunteered to participate in this study and all gave their written informed consent. The study was approved by the King's College Hospital Ethics Committee. Twenty four patients received theophylline (mean age $26 \pm 4.6$ yrs) and 12 received placebo (mean age $28 \pm 6.8$ yrs). All subjects were treated with $\beta_{2}$-adrenoceptor agonists on demand and had a baseline forced expiratory volume in one second $(\mathrm{FEV} 1)>70 \%$ predicted. Criteria for entry to the study were a positive skin test to one or more common airborne allergens, a history of asthma and a methacholine $\mathrm{PC}_{20}<16 \mathrm{mg} \cdot \mathrm{mL}^{-1}$. Patient characteristics are shown in table 1 .

Table 1. - Demographics, baseline lung function, methacholine sensitivity ( $\mathrm{PC}_{20}$ ) and slope values before commencement of placebo or theophylline treatment in those subjects who completed the study

\begin{tabular}{lcc}
\hline Characteristics & Placebo & Theophylline \\
\hline Subjects n & 10 & 18 \\
Sex M/F & $7 / 3$ & $10 / 8$ \\
Age yrs & $28.1 \pm 2.4$ & $25.6 \pm 0.9$ \\
Age range yrs & $19-39$ & $21-36$ \\
FEV $1 \%$ pred & $103.5 \pm 3.8$ & $96.1 \pm 2.2$ \\
Baseline FEV $1 \mathrm{~L}$ & $4.04 \pm 0.24$ & $3.60 \pm 0.19$ \\
$\%$ Reversibility & $16.5 \pm 3.2$ & $12.6 \pm 1.9$ \\
PC20 mg.mL & $0.82(0.39-1.74)$ & $0.86(0.49-1.51)$ \\
Slope \% FEV1 & $13.0(9.1-18.6)$ & $15.3(12.9-18.1)$ \\
mL·mg-1 & &
\end{tabular}

Results are expressed as mean \pm SEM. Values in parenthesis represent upper and lower values of the $95 \%$ confidence interval. The provocative concentration of methacholine causing a $20 \%$ fall in the forced expiratory volume in one second (PC20) and the slope are expressed as geometric means with $95 \%$ confidence limits. Slope is defined as fall in forced expiratory volume in one second (FEV1; \% saline) per doubling dose of methacholine $\left(\mathrm{mg} \cdot \mathrm{mL}^{-1}\right){ }^{+}$: fall in FEV1 following inhalation of salbutamol. M: male; F: female.

\section{Study design}

Subjects who volunteered for this study were randomized into a parallel, placebo-controlled, two-group study. After an initial screening day, subjects were assessed at baseline on entering the study (B0) and then 4 days (T1) and 2 months (T2) after commencement of placebo or theophylline treatment (median dose $250 \mathrm{mg}$ twice daily; range $250-375 \mathrm{mg}$ twice daily).

At each visit, FEV1 was determined in subjects before and after inhalation of saline $(0.9 \%)$ and after bronchial provocation with increasing doses of inhaled methacholine $\left(1.25-256 \mathrm{mg} \cdot \mathrm{mL}^{-1}\right)$. Following each challenge, three recordings of FEV1 were made and the average was taken for all subsequent analysis.

Blood samples $(15 \mathrm{~mL})$ were obtained from an antecubital vein and the percentage of circulating eosinophils was enumerated. Phenotypic analyses of peripheral blood lymphocytes were performed by two-colour cytofluorimetry using a FACSCAN (Becton-Dickinson, Cockeysveille, $\mathrm{MD}, \mathrm{USA}$ ) and monoclonal antibodies to CD3, CD4, CD8 and CD25 (Becton-Dickinson). Plasma eosinophil cationic protein (ECP) was measured by radioimmunoassay (Pharmacia, Uppsala, Sweden).

\section{Measurements}

Spirometric measurements (FEV1) were obtained using a dry wedge bellows spirometer (Vitalograph, Buckingham, UK). Serial dilutions of methacholine hydrochloride (Sigma Chemicals, Poole, UK) were prepared by the hospital pharmacy, using a diluent of normal saline with $0.5 \%$ chlorbutol BP and ranging from $1.25-256 \mathrm{mg} \cdot \mathrm{mL}^{-1}$. Challenges were performed using a modification of the method of СосксRоғт et al. [11]. Solutions were nebulized in a Wright nebulizer calibrated to an output of $0.13 \mathrm{~mL} \cdot \mathrm{min}^{-1}$ at an airflow of $7 \mathrm{~L} \cdot \mathrm{min}^{-1}$. Inhalation was by tidal breathing for 2 min from a loosely fitted face mask using a noseclip. FEV1 was first measured three times to provide a baseline for the day and then the diluent was inhaled. Measurements of FEV1 were made at 30-90 s after inhalation, the lower result serving as a baseline value for the challenge. Methacholine challenge commenced with 1.25 $\mathrm{mg} \cdot \mathrm{mL}^{-1}$ and measurements of FEV 1 were made as outlined above. Doubling concentrations of methacholine were given at 5 min intervals until either FEV 1 fell $>60 \%$ from the post-saline value, a concentration of $256 \mathrm{mg} \cdot \mathrm{mL}^{-1}$ was given or increasing asthma symptoms necessitated termination of the test.

\section{Statistical analysis}

Bronchoconstriction in response to each dose of methacholine was expressed as a percentage fall in FEV 1 from the post-saline value. FEV1 was plotted against the $\log _{2}$ concentration of methacholine and the $\mathrm{PC}_{20}$ was calculated by interpolation from the dose-response curve.

In order to calculate the slope of the dose-response curve, two approaches were adopted and the results compared. In the first case (method 1), the following criterion was applied to discard a terminal plateau at high methacholine concentrations. If the decrease in FEV1 expressed 
as a percentage of saline value was $<10 \%$ for three consecutive doses (starting with one-quarter of the highest dose administered), the result for the highest dose was not considered. The same procedure was then applied for the remaining three highest doses, etc., thereby moving concentration triplets representing two doubling doses by stepwise halving of the doses. In order to protect the linear range against the inclusion of an initial plateau, only the last value of triplets with FEV1 decreases of $<10 \%$ was included in the linear section. In the special case in which only two initial concentrations were left in this stepwise procedure, FEV 1 had to differ $\breve{S} 10 \%$.

In the second case (method 2), the doses of methacholine that produced a 10,20,30, 40 and $50 \%$ fall in FEV1 $\left(\mathrm{PC}_{\mathrm{x}}\right)$ were interpolated from each individual curve and a linear regression was performed. Linear regression was performed with only three or four data points in circumstances where a value could not be interpolated for PC10 (n: B0; T1; T2; placebo 9, 10, 9 versus theophylline $17,14,18), \mathrm{PC}_{20}(10,10,10$ versus $18,17,18), \mathrm{PC} 30$ (10, $10,10$ versus $18,18,17), \mathrm{PC} 40(10,10,10$ versus 18,16 , $16)$ and PC50 $(9,9,9$ versus $14,12,13)$.

In both cases, the geometric mean and $95 \%$ confidence interval were calculated from the individual slope values and for airway sensitivity (PC20). Two-sided comparisons within groups were made using the paired t-test after logarithmic transformation and comparison between treatments was performed using independent t-tests after logarithmic transformation. The nonparametric Mann-Whitney U-test (two-sided) was used to determine differences between groups for cell data and supplemental data for $\beta$-agonist usage. A p-value $<0.05$ was considered statistically significant.

\section{Results}

\section{Demographic data}

Thirty six subjects were randomized into the study, but data from only 28 subjects (17 males, 11 females; age: placebo $28.2 \pm 2.4 \mathrm{yrs}$ versus theophylline $25.6 \pm 0.9 \mathrm{yrs}$ $($ mean \pm SE)) were used in the analysis, as six subjects did not complete the study (one subject in the placebo group was unable to attend owing to work commitments and one developed scabies which required drug treatment; and the other four subjects in the theophylline group did not complete because of emigration, insomnia, persistent nausea and vomiting, and a road traffic accident requiring hospitalization and surgery). Data were not analysed from two subjects in the theophylline group, since they responded to the first dose of methacholine with a fall in FEV1 of $60 \%$ and $55 \%$ at $\mathrm{B} 0$ and $\mathrm{T} 1$ respectively; thus, methacholine PC20 and slope measurements could not be made.

Baseline spirometry and dose-response data from the two groups are presented in table 1 . There was no significant difference in baseline FEV $1, \mathrm{FEV}_{1} \%$ pred, \% reversibility to salbutamol, methacholine $\mathrm{PC} 20$ and slope value between the two groups. There was no significant alteration in baseline FEV1 following 4 days (T1) and 2 months (T2) of treatment with theophylline compared with baseline FEV1 before (B0) treatment (FEV1: B0 3.60土0.19 L,

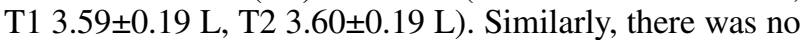

significant change in baseline FEV1 in the placebo arm of the study treatment (FEV1: B0 4.04 $\pm 0.24 \mathrm{~L}, \mathrm{~T} 13.84 \pm 0.21$ $\mathrm{L}, \mathrm{T} 24.01 \pm 0.17 \mathrm{~L}$ ).

Plasma levels of theophylline following 2 months of treatment (T2) were $11.3 \mathrm{mg} \cdot \mathrm{mL}^{-1}$ (SD 3.2, $\mathrm{n}=15$ ). The number of puffs of concomitant salbutamol medication (median (min-max): placebo $0.7(0.1-1.3), \mathrm{n}=6$ versus theophylline $0.2(0-2.9), n=11)$ and number of days of supplemental medication (placebo $59.5(56-83), \mathrm{n}=6$ versus theophylline $53(1-60), n=11)$ were not significantly different between the two groups.

\section{Airway responsiveness}

Methacholine produced a dose-dependent fall in FEV1 in both placebo and theophylline groups (fig. 1). Mean methacholine PC20 values before (B0) and after 4 days (T1) and 2 months (T2) of treatment with either placebo
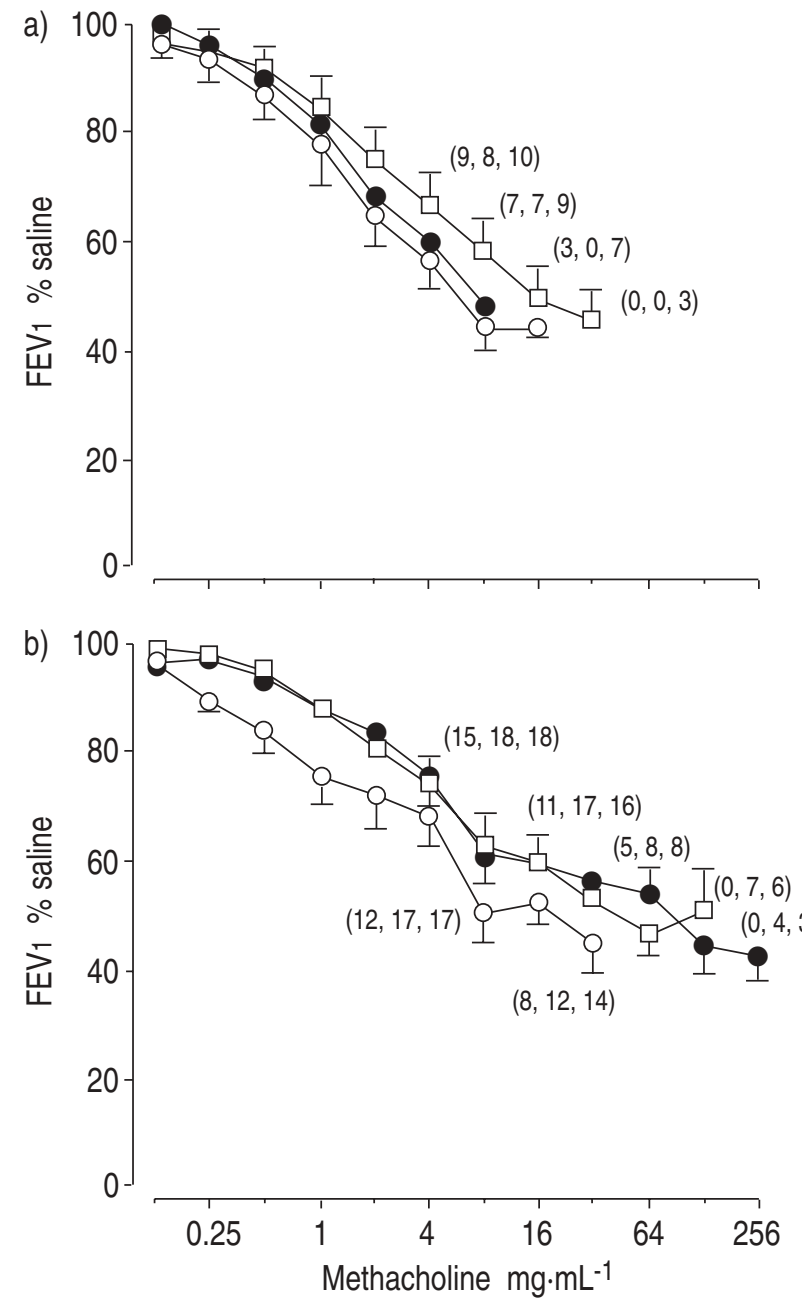

Fig. 1. - Mean dose-response curves (percentage fall in forced expiratory volume in one second (FEV1) from postsaline FEV1) before (B0, O) and after 4 days $(\mathrm{T} 1, \bullet)$ and 2 months $(\mathrm{T} 2, \boldsymbol{})$ of: a) placebo or b) theophylline treatment. Each point represents the mean and the vertical lines represent SEM. For the sake of clarity the error bars have been omitted from $\mathrm{T} 1$, but vary between 1 and $7 \%$. Unless otherwise specified, the number of subjects used to calculate the mean at each point was 10 and 18 for the placebo and theophylline group, respectively. In other cases, the number of subjects are indicated in parenthesis (B0, T1, T2, respectively). 
or theophylline are shown in table 2 . There was a statistically significant reduction in methacholine sensitivity (geometric mean (95\% confidence limits)) 2 months after treatment with theophylline (T2/B0: 3.17 (1.41-7.13), $\mathrm{p}=$ 0.008 , two-tailed), but not after treatment with placebo (T2/B0: 1.84, 0.86-3.95).

Mean slope values for the methacholine dose-response curves before (B0) and following 2 months (T2) of treatment with placebo and theophylline are shown in table 3 . There was a statistically significant reduction in slope 2 months after treatment with theophylline (T2/B0: 0.80 (0.67-0.97), $\mathrm{p}=0.023$, two-tailed), but not with placebo (T2/B0: 0.98 (0.67-1.44)).

The method of linear regression of the $\mathrm{PC}_{\mathrm{x}}$ versus methacholine (fig. 2) yielded similar results to those des-cribed above. Thus, there was a statistically significant reduction in slope 2 months after treatment with theophylline (T2/ B0: 0.75 (0.58-0.96)), $\mathrm{p}=0.029$, two-tailed), but not with placebo (T2/B0: $0.79(0.46-1.36))$.

\section{Cell data}

Various indices of inflammation were measured in peripheral blood samples obtained before and after 2 months of theophylline treatment. The median data are presented in table 4 . The percentage of blood eosinophils was not significantly reduced after 2 months of treatment with theophylline compared with placebo. Similarly, theophylline treatment had no significant effect on the percentage of various lymphocyte subpopulations in peripheral blood compared with placebo treatment (table 4).

Table 2. - Airway responsiveness to methacholine (mg. $\left.\mathrm{mL}^{-1}\right)$ as assessed by sensitivity $\left(\mathrm{PC}_{20}\right)$ before $(\mathrm{B} 0)$ and after 2 months (T2) of treatment with placebo and theophylline

\begin{tabular}{lcl}
\hline Treatment period & $\begin{array}{c}\text { Placebo } \\
\mathrm{n}=10\end{array}$ & $\begin{array}{c}\text { Theophylline } \\
\mathrm{n}=18\end{array}$ \\
\hline B0 & $0.82(0.39-1.74)$ & $0.86(0.49-1.51)$ \\
T2 & $1.52(0.63-3.65)$ & $2.73(1.66-4.50)$ \\
T2/B0 & $1.84(0.86-3.95)$ & $3.17 *(1.41-7.13)$ \\
\hline
\end{tabular}

Results are expressed as geometric mean and $95 \%$ confidence limits. PC20: provocative concentration of methacholine causing a $20 \%$ fall in the forced expiratory volume in one second. *: significant increase in $\mathrm{PC} 20$ in the theophylline group ( $\mathrm{p}=0.008$, two-sided); no significant differences between groups.

Table 3. - Slope of methacholine dose-response curve before (B0) and after 4 days (T1) and 2 months (T2) of treatment with placebo and theophylline

\begin{tabular}{lccc}
\hline Treatment period & $\begin{array}{c}\text { Placebo } \\
\mathrm{n}=10\end{array}$ & $\begin{array}{c}\text { Theophylline } \\
\mathrm{n}=18\end{array}$ \\
\hline B0 & $13(9.1-18.6)$ & 15.3 & $(12.9-18.1)$ \\
T1 & $16.1(12.8-20.3)$ & 13.7 & $(11.2-16.9)$ \\
T2 & $12.8(8.9-18.3)$ & $12.3 \quad(10.5-14.3)$ \\
T1/B0 & $1.24(0.97-1.58)$ & $0.90(0.72-1.13)$ \\
T2/B0 & $0.98(0.67-1.44)$ & $0.80^{*}(0.67-0.97)$
\end{tabular}

Results based on method 1 are given as geometric mean and 95\% confidence limits. Slope is defined as the fall in forced expiratory volume in one second (FEV1) (\% saline) per doubling dose of methacholine $\left(\mathrm{mg} \cdot \mathrm{mL}^{-1}\right)$. *: significant reduction in slope value in the theophylline group ( $\mathrm{p}=0.023$, two-sided); no significant differences between groups.
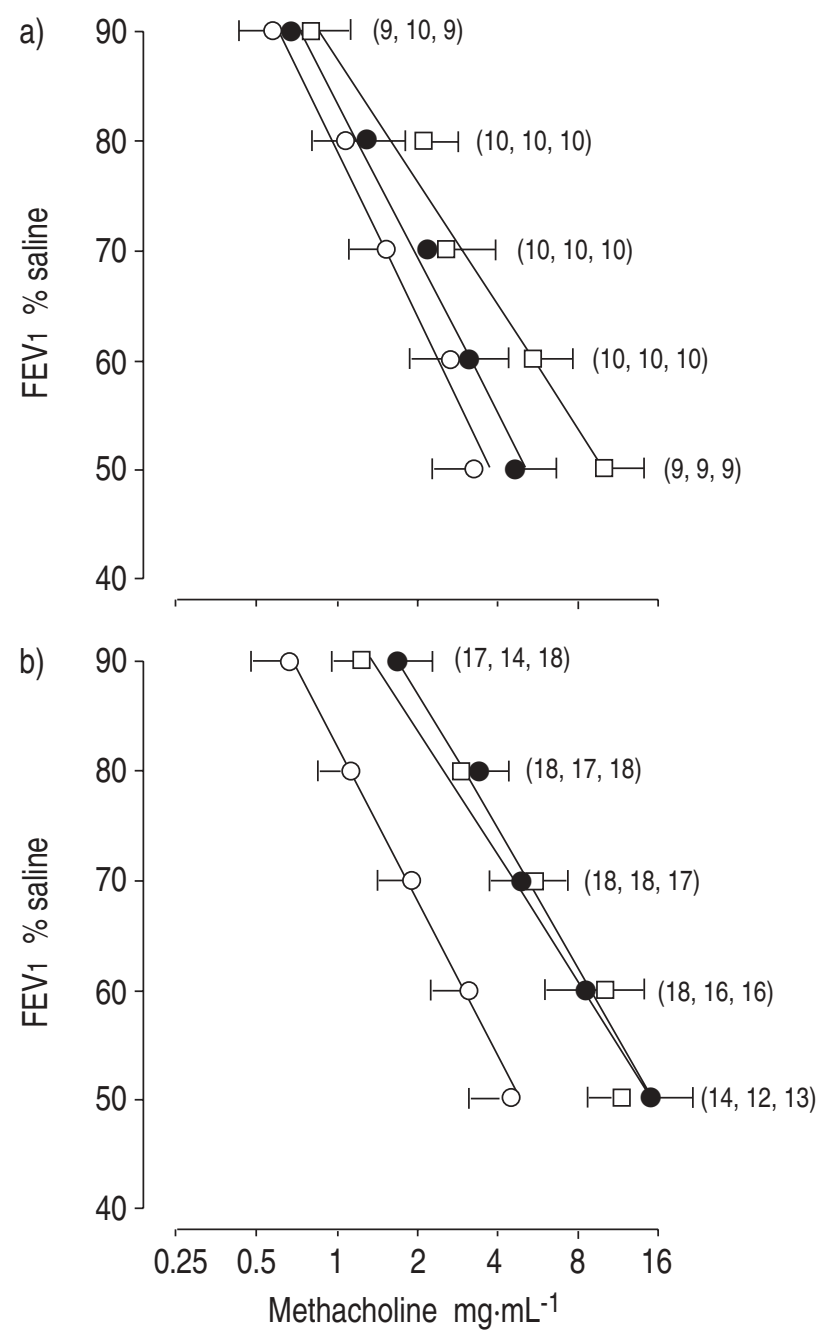

Fig. 2. - Mean dose-response curves (percentage fall in forced expiratory volume in one second $\left(\mathrm{FEV}_{1}\right)$ from postsaline FEV1) before (B0, O) and after 4 days $(\mathrm{T} 1, \bullet)$ and 2 months $(\mathrm{T} 2, \square)$ of: a) placebo or b) theophylline treatment. Provocative concentration (PC)10, PC20, PC 30, $\mathrm{PC} 40$ and $\mathrm{PC} 50$ values were interpolated from individual dose-response curves, each point represents the mean and horizontal lines represent SEM. The number of subjects used to calculate the mean at each point is indicated in parenthesis (B0, T1, T2, respectively).

A number of activation markers for inflammatory cells was also measured and, as the results show, theophylline treatment had no significant effect on either the level of plasma ECP or the percentage of CD25+ T-lymphocytes compared with placebo (table 4).

\section{Discussion}

Theophylline treatment did not significantly alter baseline FEV 1 but reduced methacholine sensitivity following 2 months of treatment. Similarly, theophylline significantly reduced the slope of the methacholine dose-response curve after 2 months of treatment, which was not observed after treatment with placebo. These data suggest that theophylline treatment can reduce airway reactivity to spasmogens, which is unlikely to be due to bronchodilation as it was not associated with changes in baseline FEV1. 
Table 4. - Inflammatory cell number and activation status in subjects before (B0) and after 2 months (T2) of treatment with placebo and theophylline

\begin{tabular}{|c|c|c|c|}
\hline & B0 & $\mathrm{T} 2$ & $\mathrm{~T} 2 / \mathrm{B} 0$ \\
\hline \multicolumn{4}{|l|}{ Placebo $n=10$} \\
\hline Blood eosinophils \% & $3.85(3.3-4.5)$ & $3.40(2.7-4.3)$ & $0.91(0.70-1.20)$ \\
\hline $\mathrm{ECP} \mu \mathrm{g} \cdot \mathrm{L}^{-1}$ & $12.0(6.6-21.6)$ & $12.1(6.4-22.7)$ & $0.97(0.50-1.98)$ \\
\hline $\mathrm{CD} 3+\%$ & $70.1(65.0-75.6)$ & $71.4(67.2-75.9)$ & $1.02(0.94-1.11)$ \\
\hline CD4+/CD3+ \% & $59.7(53.8-66.8)$ & $56.8(52.7-62.3)$ & $0.96(0.91-1.00)$ \\
\hline CD8+/CD3+ \% & $35.1(31.2-39.4)$ & $37.3(33.6-41.4)$ & $1.06(0.99-1.14)$ \\
\hline CD25+/CD4+ \% & $24.9(19.3-32.3)$ & $26.6(18.6-38.1)$ & $1.07(0.76-1.50)$ \\
\hline $\mathrm{CD} 25+/ \mathrm{CD} 8+\%$ & $1.97(1.21-3.20)$ & $2.11(1.51-2.94)$ & $1.01(0.62-1.64)$ \\
\hline \multicolumn{4}{|l|}{ Theophylline $n=18$} \\
\hline Blood eosinophils \% & $3.8(3.3-4.4)$ & $3.7(3.0-4.7)$ & $0.95(0.76-1.3)$ \\
\hline $\mathrm{ECP} \mu \mathrm{g} \cdot \mathrm{L}^{-1}$ & $21.0(13.4-33.1)$ & $14.4(7.2-28.8)$ & $0.69(0.37-1.31)$ \\
\hline $\mathrm{CD} 3+\%$ & $69.6(66.7-72.6)$ & $67.3(63.0-72.0)$ & $0.97(0.92-1.02)$ \\
\hline CD4+/CD3+ \% & $58.0(54.9-61.2)$ & $58.5(54.7-62.5)$ & $1.01(0.97-1.05)$ \\
\hline CD8+/CD3+ \% & $39.1(36.6-42.1)$ & $38.5(35.3-41.9)$ & $0.98(0.94-1.03)$ \\
\hline CD25+/CD4+ \% & $22.4(17.6-28.4)$ & $23.0(17.5-30.3)$ & $1.10(0.77-1.56)$ \\
\hline $\mathrm{CD} 25+/ \mathrm{CD} 8+\%$ & $2.55(1.57-4.16)$ & $2.56(1.67-3.93)$ & $1.00(0.57-1.75)$ \\
\hline
\end{tabular}

Results are expressed as geometric mean and $95 \%$ confidence limits in parenthesis. ECP: eosinophil cationic protein.

Furthermore, unlike short- and long-acting $\beta_{2}$-adrenoceptor agonists $[15,16]$, theophylline does not cause a worsening of the slope of the dose-response curve to methacholine in mild asthmatics.

A number of studies has investigated the effect of antiasthma drugs on the shape of the dose-response curve to spasmogens. Thus, salbutamol $[15,16]$ and salmeterol [16] provide protection against bronchospastic agents, as assessed by rightward shifts in the dose-response curve to spasmogens. However, prolonged use of salbutamol or terbutaline reduces the protection afforded against bronchoconstriction induced by methacholine [21-23], exercise [24] or antigen challenge [21, 23] and has been shown to increase the magnitude of the late asthmatic response induced by allergen [25]. Similarly, regular treatment with salmeterol also leads to a loss in protection against bronchospasm induced by methacholine [26, 27] and exercise [28]. Furthermore, $\beta_{2}$-adrenoceptor agonists have been demonstrated to steepen the dose-response curve to methacholine $[15,16]$. The slope of the dose-response curve is thought to reflect the degree of airway narrowing and may represent an index of thickened airway wall secondary to inflammation [14]. These findings suggest that $\beta_{2}$-adrenoceptor agonists, while providing effective bronchoprotection acutely, may mask the potential for rapid bronchoconstriction following exacerbation of airway narrowing, particularly following regular therapy $[15,16]$. In contrast, glucocorticosteroids such as budesonide [17] and fluticasone [18] reduce the slope and restore the plateau of the dose-response curve to methacholine, observations which have been taken as evidence that, unlike $\beta_{2}$-adrenoceptor agonists, glucocorticosteroids can reduce airway wall thickening by virtue of their anti-inflammatory properties.

The observations with chronic theophylline treatment suggest that theophylline behaves more like a glucocorticosteroid than a $\beta_{2}$-adrenoceptor agonist in causing a rightward shift in the dose-response curve to inhaled methacholine. It is clear, however, that the effect of theophylline is modest compared with inhaled glucocorticosteroids, although it is possible that a longer treatment period may have had a greater effect. Certainly, theophylline has now been shown to have many properties like glucocorticosteroids, including the ability to attenuate allergen-induced late asthmatic responses following single $[1,2]$ and regular prophylactic $[4,5]$ treatment. Again, these observations are in contrast to recent observations showing that regular $\beta_{2}$-adrenoceptor agonists exacerbate responses to allergen $[21,23,25]$, suggesting that the beneficial effect of theophylline is unlikely to be due to bronchodilation. Furthermore, treatment with theophylline, like glucocorticosteroids, causes a reduction in the number and activation state of inflammatory cells as assessed in bronchial biopsies and bronchoalveolar lavage [6-8]. These observations are again in contrast to regular treatment with $\beta_{2}$-adrenoceptor agonists [29]. Collectively, these studies support the view that theophylline possesses antiinflammatory activity and it, like glucocorticosteroids, can influence the shape of the dose-response curve to methacholine, albeit to a lesser extent.

However, following 2 months of treatment with theophylline there was no significant effect on the percentage of eosinophil and T-lymphocyte subsets in peripheral blood. Furthermore, there was no significant change in the expression of activation markers including ECP and CD25+ for eosinophils and T-lymphocytes, respectively. These observations are in contrast to a number of studies that have shown that treatment with theophylline can increase the number and activity of suppressor/cytotoxic Tlymphocytes in the peripheral blood of asthmatics [30, 31]. Moreover, it has previously been demonstrated that theophylline attenuated the increase in the number of circulating CD4+ T-lymphocytes but not eosinophils $48 \mathrm{~h}$ after antigen challenge [4]. Similarly, the number and activation status of eosinophils and T-lymphocytes in bronchial biopsies [6] and bronchoalveolar lavage [7] was significantly reduced in theophylline-treated subjects $24 \mathrm{~h}$ after antigen challenge. Clearly, changes in cell number and activation markers are more readily detected in bronchial biopsies and bronchoalveolar lavage than in peripheral blood. It is not possible from the present study to know whether the effect of theophylline on airway reactivity was associated with a reduction in the number or activation status of inflammatory cells in the airways. It is clear from these results that the effect of theophylline on the dose-response curve to inhaled methacholine is evident at 4 days post-treatment and that this effect persists. The basis of this effect is not yet known, but could result from the ability of theophylline to inhibit airway nerves, when occurring at lower concentrations than required to induce airway smooth muscle relaxation [29]. Such an 
interpretation is clearly consistent with the observations that theophylline could influence the methacholine dose-response curve without causing significant bronchodilation.

In conclusion, this investigation has revealed that prolonged treatment with theophylline was associated with a significant change in the sensitivity and slope of the methacholine dose-response curve that was qualitatively similar to that observed following regular treatment with glucocorticoids, albeit to a lesser extent. Nonetheless, the results would suggest that theophylline may have effects complementary to glucocorticosteroids, an interpretation recently supported by evidence showing that the addition of theophylline to glucocorticosteroid therapy is clinically beneficial [32].

\section{References}

1. Pauwels R, van Renterghem D, van der Straeten M, Johannesson N, Persson CG. The effect of theophylline and enprofylline on allergen-induced bronchoconstriction. J Allergy Clin Immunol 1985; 76: 583-590.

2. Mapp C, Boschetto P, dal Vecchio L, et al. Protective effect of antiasthma drugs on late asthmatic reactions and increased airway responsiveness induced by toluene diisocyanate in sensitized subjects. Am Rev Respir Dis 1987; 136: 1403-1407.

3. Cockcroft DW, Murdock KY, Gore BP, O'Byrne PM, Manning P. Theophylline does not inhibit allergen-induced increase in airway responsiveness to methacholine. $J$ Allergy Clin Immunol 1989; 83: 913-920.

4. Ward AJ, McKenniff M, Evans JM, Page CP, Costello JF. Theophylline- an immunomodulatory role in asthma? Am Rev Respir Dis 1993; 147: 518-523.

5. Hendeles L, Harman E, Huang D, O'Brien R, Blake K, Delafuente J. Theophylline attenuation of airway responses to allergen: comparison with cromolyn metered-dose inhaler. J Allergy Clin Immunol 1995; 95: 505-514.

6. Sullivan P, Bekir S, Jaffar Z, Page C, Jeffery P, Costello J. Anti-inflammatory effects of low-dose oral theophylline in atopic asthma [published erratum appears in Lancet 1994; 343: 1512]. Lancet 1994; 343: 1006-1008.

7. Jaffar ZH, Sullivan P, Page CP, Costello J. Low-dose theophylline modulates T-lymphocyte activation in allergenchallenged asthmatics. Eur Respir J 1996; 9: 456-462.

8. Finnerty JP, Lee C, Wilson S, Madden J, Djukanovic R, Holgate ST. Effects of theophylline on inflammatory cells and cytokines in asthmatic subjects: a placebo-controlled parallel group study. Eur Respir J 1996; 9: 1672-1677.

9. Brenner M, Berkowitz R, Marshall N, Strunk RC. Need for theophylline in severe steroid-requiring asthmatics. Clin Allergy 1988; 18: 143-150.

10. Kidney J, Dominguez M, Taylor PM, Rose M, Chung KF, Barnes PJ. Immunomodulation by theophylline in asthma. Demonstration by withdrawal of therapy. Am J Respir Crit Care Med 1995; 151: 1907-1914.

11. Cockcroft DW, Killian DN, Mellon JJ, Hargreave FE. Bronchial reactivity to inhaled histamine: a method and clinical survey. Clin Allergy 1977; 7: 235-243.

12. De Monchy JG, Kauffman HF, Venge P, et al. Bronchoalveolar eosinophilia during allergen-induced late asthmatic reactions. Am Rev Respir Dis 1985; 131: 373-376.

13. Cockcroft DW, Ruffin RE, Dolovich J, Hargreave FE. Allergen-induced increase in non-allergic bronchial reactivity. Clin Allergy 1977; 7: 503-513.

14. Sterk PJ, Bel EH. Bronchial hyperresponsiveness: the need for a distinction between hypersensitivity and excessive airway narrowing. Eur Respir J 1989; 2: 267-274.
15. Bel EH, Zwinderman AH, Timmers MC, Dijkman JH, Sterk PJ. The protective effect of a beta 2 agonist against excessive airway narrowing in response to bronchoconstrictor stimuli in asthma and chronic obstructive lung disease. Thorax 1991; 46: 9-14.

16. Wong AG, O'Shaughnessy AD, Walker CM, Sears MR. Effects of long-acting and short-acting $\beta$-agonists on methacholine dose-response curves in asthmatics. Eur Respir J 1997; 10: 330-336.

17. Bel EH, Timmers MC, Zwinderman AH, Dijkman JH, Sterk PJ. The effect of inhaled corticosteroids on the maximal degree of airway narrowing to methacholine in asthmatic subjects. Am Rev Respir Dis 1991; 143: 109-113.

18. Overbeek SE, Rijnbeek PR, Vons C, Mulder PG, Hoogsteden HC, Bogaard JM. Effects of fluticasone propionate on methacholine dose-response curves in nonsmoking atopic asthmatics. Eur Respir J 1996; 9: 2256-2262.

19. Koeter GH, Kraan J, Boorsma M, Jonkman JH, van der Mark TW. Effect of theophylline and enprofylline on bronchial hyperresponsiveness. Thorax 1989; 44: 1022-1026.

20. Crescioli S, Spinazzi A, Plebani M, et al. Theophylline inhibits early and late asthmatic reactions induced by allergens in asthmatic subjects. Ann Allergy 1991; 66: 245-251.

21. Cockcroft DW, McParland CP, Britto SA, Swystun VA, Rutherford BC. Regular inhaled salbutamol and airway responsiveness to allergen. Lancet 1993; 342: 833-837.

22. O'Connor BJ, Aikman SL, Barnes PJ. Tolerance to the nonbronchodilator effects of inhaled beta 2-agonists in asthma. N Engl J Med 1992; 327: 1204-1208.

23. Bhagat R, Swystun VA, Cockcroft DW. Salbutamol-induced increased airway responsiveness to allergen and reduced protection versus methacholine: dose response. $J$ Allergy Clin Immunol 1996; 97: 47-52.

24. Inman MD, O'Byrne PM. The effect of regular inhaled albuterol on exercise-induced bronchoconstriction. Am J Respir Crit Care Med 1996; 153: 65-69.

25. Cockcroft DW, O'Byrne PM, Swystun VA, Bhagat R. Regular use of inhaled albuterol and the allergen-induced late asthmatic response. J Allergy Clin Immunol 1995; 96 : 44-49.

26. Bhagat R, Kalra S, Swystun VA, Cockcroft DW. Rapid onset of tolerance to the bronchoprotective effect of salmeterol. Chest 1995; 108: 1235-1239.

27. Cheung D, Timmers MC, Zwinderman AH, Bel EH, Dijkman JH, Sterk PJ. Long-term effects of a long-acting beta 2-adrenoceptor agonist, salmeterol, on airway hyperresponsiveness in patients with mild asthma. $N$ Engl $J$ Med 1992; 327: 1198-1203.

28. Ramage L, Lipworth BJ, Ingram CG, Cree IA, Dhillon DP. Reduced protection against exercise induced bronchoconstriction after chronic dosing with salmeterol. Respir Med 1994; 88: 363-368.

29. Barlinski J, Lockhart A, Frossard N. Modulation by theophylline and enprofylline of the excitatory non-cholinergic transmission in guinea-pig bronchi. Eur Respir $J$ 1992; 5: 1201-1205.

30. Fink G, Mittelman M, Shohat B, Spitzer SA. Theophylline-induced alterations in cellular immunity in asthmatic patients. Clin Allergy 1987; 17: 313-316.

31. Shohat B, Volovitz B, Varsano I. Induction of suppressor $\mathrm{T}$ cells in asthmatic children by theophylline treatment. Clin Allergy 1983; 13: 487-493.

32. Evans DJ, Taylor DA, Zetterstrom O, Chung KF, O'Connor BJ, Barnes PJ. A comparison of low-dose inhaled budesonide plus theophylline and high-dose inhaled budesonide for moderate asthma. $N$ Engl J Med 1997; 337: 1412-1418. 